University for Business and Technology in Kosovo

UBT Knowledge Center

Nov 2nd, 9:00 AM - Nov 3rd, 5:00 PM

\title{
The Role of The Technology in Developing Economies - Case of
}

\author{
Albania \\ Pranvera Resulaj \\ University of Vlora \\ Edmira Cakrani \\ University of Vlora
}

Follow this and additional works at: https://knowledgecenter.ubt-uni.net/conference

Part of the Business Commons

\section{Recommended Citation}

Resulaj, Pranvera and Cakrani, Edmira, "The Role of The Technology in Developing Economies - Case of Albania" (2012). UBT International Conference. 41.

https://knowledgecenter.ubt-uni.net/conference/2012/all-events/41

This Event is brought to you for free and open access by the Publication and Journals at UBT Knowledge Center. It has been accepted for inclusion in UBT International Conference by an authorized administrator of UBT Knowledge Center. For more information, please contact knowledge.center@ubt-uni.net. 


\title{
The Role of The Technology in Developing Economies - Case of Albania
}

\author{
PhD. Pranvera Resulaj ${ }^{1}$, PhD. Candidate Edmira Cakrani ${ }^{1}$ \\ ${ }^{1}$ Department of Economics; University of Vlora "Ismail QemaIi"
}

\begin{abstract}
We propose a theory of Economic Development in which technology adoption and barriers to such adoption are the focus. The size of these barriers differs across countries and time. The larger these barriers, the greater the investment a society must take to adopt a more advanced technology.

The model base lied to the western countries, which have received a great and huge development of technology and goes away in an observation about the adaption of such technology by Albanian Economy, as a developing country. We are focus in identification of the main barriers affronted by Albania Economy finding the correlation between the difficulties in adaptation with such technology and the Albania social and economic environment.

After twenty long years of transition we recommend, as the main road which will lead in an economic development based on the more advanced technology, the strongest Reform in Education.
\end{abstract}

\section{Key words: Technology transfer, knowledge, developed countries, developing countries}

\section{Introduction}

The transfer of technology from developed countries to emerging markets has been of central interest. A list of problems is associated with technology transfer in the context of Central and Eastern European countries. We argue that different country institutional characteristics are determinants of technology transfer. By outlining the recent socio-economic changes in the region, we consider the adoption of essential market institutions and the specific norms of regional integration with the European Union as the most important determinants.

But we emphases that "the differences in the scientific and technological infrastructure and in the popularization of the science are the most important causes of differential economic and social levels.

The model base lied to the western countries, which have received a great and huge development of technology and goes away in an observation about the adaption of such technology by Albanian Economy, as a developing country. We are focus in identification of the main barriers affronted by Albania Economy finding the correlation between the difficulties in adaptation with such technology and the Albania social and economical environment.

After twenty long years of transition we recommend, as the main road which will lead in an economic development based on the more advanced technology, the strongest Reform in Education.

The main objective of the assessment has been to rank countries' performance and to identify the barriers of reaching such a performance from Albanian Economy. Thus, it can assist Region's economies to:

1. Learn to each -other experience

2. Identify good practices in policy elaboration and implementation

3. Identify strengths and weakness at national and regional levels

4. Improve policy planning and

5. Contribute to the definition of policy priorities and policy targets

\section{A BRIEF OVERVIEW ON THE HISTORY OF INSTITUTIONS, SCIENCE, TECHNOLOGY AND DEVELOPMENT}

Technology diffusion creates major benefits: the more a technology is used, the greater the likelihood of further improvement. The wide diffusion of a technology allows the development of economies of scale and reduction of cost; and access to technologies by all countries, including the non development one, is es sential to face the global challenges.

Adaption requires not only a massive effort to develop suitable technologies but mechanisms to make them readily available on an affordable basis through technology transfer and extensive international cooperation. Innovation is not enough.

In view of the dimensions and urgency of the technological demand generated by global economical change, the commitment of governments to ensure access to needed technologies by developing countries is indispensable. In the absence of such actions, this essentially global problem for development countries will not find a global solution, but will be in total dependence of those that posses the capital and technical capabilities to produce new technologies.

1.1 Science and Technology in Developed and Developing Countries

There are significant social and economic differences between developed and developing countries. Many of the underlying causes of these differences are rooted in the long history of development of such countries include social, cultural and econ omic variables, historical and political elements, international relations, geographical factors. This is only one part of medallion. The 
differences in the scientific and technological infrastructure and in the popularization of the science are the most importan $\mathrm{t}$ causes of differential economic and social levels. In this technological progress an important role has played the educational system. This is one of the key factors, which has contributed to economic success of some noted and developed countries.

Take technological transfer as an example. The codified technical information assumes a whole background and practices that might be very incomplete in a developing country. Implementing a new technology in a rather different environment is itself a creative act, not just a copied behavior (Joseph Stiglitz; Public Policy for a Knowledge Economy). Getting a complex technical system to function near its norms or repairing when it's something which cannot be easily transferred or downloaded to a developing country. As consequence we can imagine the problem in "transferring" the economic institutions of a private property market economy to developing countries.

Today, in the developed countries basic and applied scientific research is an essential investment in the lo ng-term welfare. In the universities they assign highest priority to stimulating and nurturing scientific and technical talent and to the training of students. From this priority has emerged the close association of education and economical growth. The eco nomical growth can by its part finance and support scientific education in Universities.

\subsection{The Current Situation of the Technology on Developing Countries}

How much they are aware of the importance of science and technology? Even they are, this awareness does not necessarily make it easy to develop, and popularize science. Inadequate scientific infrastructure is a critical factor which creates strong ba rriers to the adaption of technology by developing countries, and as consequence barriers on economic dev elopment.

Another indicator of how science is of neglected importance in developing countries is that most of these countries failed to stres s that, for long term effectiveness, technology transfer should always be accompanied by science transfer.

In summary, the social and economic growth of the developed countries is dependent on an essential emphasis on education, science and technology. Meantime the basic problems of developing countries are the weak educational and scientific infrastructure, and a lack of appreciation of the importance of science as an essential ingredient of economical and social development.

Technology transfer and therefore international trade takes on even greater importance for productivity growth in developing countries, which as a group undertake little domestic R\&D and therefore have few domestic sources of new technology. According to $\mathrm{CHH}$ (1997) a 1 per cent increase in the R\&D capital stock in the industrialized countries raises output in developing countries by $0.06 \%$. Clearly the spillover to developing countries through international trade are substantial.

\subsection{Research and development expenditure (\% of GDP)}

Expenditures for research and development are current and capital expenditures (both public and private) on creative work undertaken systematically to increase knowledge, including knowledge of humanity, culture, and society, and the use of knowledge for new applications. R\&D covers basic research, applied research, and experimental development.

\section{A BRIEF OVERLOOK ON ALBANIA ECONOMY AND TECHNOLOGY}

\subsection{The interaction between Science and Technology throughout development process}

Globalization presents opportunities and challenges for developing regions such Albania as they seek to improve their levels of socioeconomic development. Processes of globalization increasingly depend upon information and communication technologies (ICTs), and these normally need modifications to fit local contexts. This requires that processes that affect interactions be tween global, regional, and local levels need to be understood. It appears reasonable to conjecture that understanding the roles or effects of socioeconomic and cultural factors (among others) would lead to more effective ICT policies for sustainable development at regional and local levels.

Since 2006, Albania has restructured its research and innovation system and introduced new strategies for research and innovation and higher education, as well as various programs for funding. Recent structures, including the Albanian Agency of Research, Technology and innovation (ARTI), National Agency for Information Society (NAIS), and the business Relay and Innovation Centre(BRIC), now playing active roles in their respective sectors, also managing program funding.

GERD (Gross Expenditure on R\&D) was $0.15 \%$ of GDP in 2008. GERD per capita was indicated as \$12.6 in PPP\$, which represent only $1.8 \%$ of the EU-27 GERD per capita recorded in 2008. Mostly the R\&D funding comes from state budget (more than $80 \%$ ) $8.6 \%$ from higher education, with only $3.3 \%$ from business enterprises. Around 7.4\% of GERD was funded from abroad in 2008. The data within the National Strategy of Science, Technology and Innovation ${ }^{\mathrm{i}} 2009-2015$ suggest that annual Gross expenditure on Research and Development was close to euro 15 million in 2009. As consequence spending on research and development was estimated less than $0.2 \%$ of GDP in 2009 (the lowest rate in Europe) and according to the Strategy GERD is to increase to $0.6 \%$ of GDP by 2015 .

The lack of comparable statistics has made it difficult comparing Albania and EU and other East -Europe and Balkan Countries Tab. 1 Share of Public Sector R\&D (in mill ALL)

\begin{tabular}{|l|l|l|l|l|l|l|l|l|l|l|l|l|}
\hline Country & 1999 & $\mathbf{2 0 0 0}$ & $\mathbf{2 0 0 2}$ & $\mathbf{2 0 0 3}$ & $\mathbf{2 0 0 4}$ & $\mathbf{2 0 0 5}$ & $\mathbf{2 0 0 6}$ & $\mathbf{2 0 0 7}$ & $\mathbf{2 0 0 8}$ & $\mathbf{2 0 0 9}$ & $\mathbf{2 0 1 0}$ & $\mathbf{2 0 1 1}$ \\
\hline
\end{tabular}




\begin{tabular}{|l|l|l|l|l|l|l|l|l|l|l|l|l|}
\hline Albania & 1,650 & 3,000 & 4,500 & 4,500 & 4,900 & 5,300 & 5,700 & 5,800 & 6,000 & 7,700 & 8,000 & 7,800 \\
\hline
\end{tabular}

Source: World Bank table below reflect the limited data on the funding and performance of Albania R\&D.

The National Strategy of Science, Technology and Innovation reports

Table 2: Basic indicators for R\&D investments in Albania

\begin{tabular}{|c|c|c|c|c|}
\hline & 2008 & 2009 & 2010 & EU Average 2010 \\
\hline GDP Growth rate & $7.5 \%$ & $3.3 \%$ & $3.9 \%$ & 2.0 \\
\hline GERD as \% of GDP & $0.15 \%$ & 0.2 & 0.2 & 2.0 \\
\hline GERD per capita & $12.6 \$$ & N/A & N/A & 490.2 \\
\hline $\begin{array}{c}\text { In this section are } \\
\text { included scientific } \\
\text { papers which are } \\
\text { selected for } \\
\text { presentation in poster } \\
\text { session in International } \\
\text { Conference in } \\
\text { Management Business } \\
\text { and Economics } \\
\text { (million euro) }\end{array}$ & N/A & $\mathrm{N} / \mathrm{A}$ & N/A & $92,729.05$ \\
\hline GBAORD as \% of GDP & N/A & N/A & N/A & 0.76 \\
\hline BERD (million euro) & 0.891 & N/A & N/A & 151125.56 \\
\hline BERD as \% of GDP & & N/A & N/A & 1.23 \\
\hline $\begin{array}{l}\text { GERD financed by abroad as \% } \\
\text { of total GERD }\end{array}$ & 7.4 & N/A & N/A & N/A \\
\hline $\begin{array}{l}\text { R\&D as \% of GERD performed } \\
\text { by HEIs }\end{array}$ & 47.9 & $\mathrm{~N} / \mathrm{A}$ & N/A & 24.2 \\
\hline $\begin{array}{l}\text { R\&D as \% of GERD performed } \\
\text { by PROs }\end{array}$ & 52.1 & $\mathrm{~N} / \mathrm{A}$ & N/A & 13.2 \\
\hline $\begin{array}{l}\text { R\&D as \% of GERD performed } \\
\text { by Business Enterprise Sector }\end{array}$ & N/A & N/A & N/A & 61.5 \\
\hline
\end{tabular}

Sources: 2011 Albania Progress Report, UNESCO

While not specifically aimed at R\$D funding for innovation initiatives under the Business Innovation and Technology Strategy (BITS) 2011-2016 totals $10.31 \mathrm{~m}$ euro, of which $4.8 \mathrm{~m}$ euro is dedicated to the Innovation Fund which awards grants to SMEs for other types of support for product development and process improvement through technology adoption, among other types of support. BITS is to be mainly funded by foreign donors (euro 7,893 m or 76.5\% is excepted from the EU and other donors).

Other financial instruments supporting R\&D in Albania include third party funding focused on STI; donation fromphysical and judicial subjects at national and international levels.

\section{INTERNATIONAL TECHNOLOGY INSTITUTIONAL DEVELOPMENT \\ TRANSFER AND THE EFFECTS OF}

The transfer of technology from developed countries to emerging markets has been of central interest. A list of problems is associated with technology transfer in the context of Central and Eastern European countries. We argue that different country institutional characteristics are determinants of technology transfer. By outlining the recent socio-economic changes in the region, we consider the adoption of essential market institutions and the specific norms of regional integration with the European Union as these most important determinants.

In countries with underdeveloped administration, bureaucratic structure, and limited industrial culture, it is very difficult to practice Technology transfer.

The Albanian European Integration shows an highly dependence from the construction of a world class infrastructure of Information and Communication Technology (TIC), which can be used by business, government and citizens.

The technology and it's commercialization together with the needed Know - How transfer are a big challenge for Albania Business since the industrial inheritance and tradition in our country do not provide much inspirations.

- New Technology. 
New Technology is mainly being brought in with Foreign Direct Investment

\subsection{Enterprises and Technology}

Strengthening SME's technological capacity

SME's technological capacity, essential for competitiveness and innovation, is slowly being strengthened. Areas such as dissemination of new technology, creation of links between SMEs and research centers to foster cooperation, establishment of research and technology centers, and initiatives to encourage the formation of clusters in economic sectors are still in the early stages.

According to the technology acceptance model (TAM), perceived ease of use and perceived usefulness constructs are believed to be fundamental in determining the acceptance and use of various IT.

\subsection{Successful e-business models and top class-business support}

Like technological capacity, e-business solutions can further improve the efficiency and competitiveness of SME's. They provide more effective approaches to purchasing and sales, facilitating access to European Markets. Donor funding has been important for the development of support facilities and services and provision of information system. However it's a strong $\mathrm{n}$ eed for more clarity, for quality standards in regard to service provision, and for better coordination of business support strat egies.

\section{OVERCOMING BARRIERS IN TECHNOLOGY'S ADAPTING PROCESS BY ALBANIA}

Innovation contributes to productivity by providing better products and better methods of production. There are three crucial managerial problems to achieve this goal:

1. To select an appropriate technology for implementation of production

2. To reach the right level of output in order to meet the market needs.

3. Reaching Production Efficiency under an optimal combination of inputs

Some questions rises about the first problem

- What is an appropriate technology?

-Who is the responsible institutions to specify the appropriate technology

-Should it be the entrepreneur to specify the technology?

\subsection{Major Constraints in Technology Development}

1. Legis lation and Regulation

2. FDI environment and lack of incentives

3. Customs and taxes

4. Insufficient Financial Markets and Products

5. Lack of Technology Institute and Counseling Service

6. Lack of Programs that would faster Innovation and Technology Transfer

7. Lack of Organized Industrial Areas and Technology Parks

\subsection{Education and Training}

As Joseph Stiglitz mention:

"A key to success in the knowledge economy is a trained labor force".

This make not surprising why so many countries are focused on educational system. In the long run, having success in the knowledge economy requires creativity and higher order cognitive skills in order to basic skills. Those countries which will rise this creativity would be more competitive.

The second key providing success to knowledge economy is training in science and technology

This for developing countries' governments means strong support to science education

The third key we consider the public support of research. What make the problem more difficulties is that there is not a bright line between basic and applied research.

Research by it's nature is a risky undertaking. Government can finance research through Tax Policy. A tax system that rewards the returns to speculative real estate in the same way that it rewards real innovation is not supporting the culture of innovation .

Entrepreneurship education and training to help increase available skills is just starting to be developed in the region. While the Western Balkan economies have engaged in cross - stakeholder dialogue concerning the development of life-long entrepreneurship learning, policies and financial accountability remain to be defined. The assessments highlights that entrepreneurship is still generally confined to traditional business areas. It recommends treating entrepreneurship as a key competence in early education. There has been good progress at the secondary education level, but efforts have generally been 
project-based and donor driven. The assessments also recommend that pilot projects have entrepreneurship policy learning objectives, as a basis for eventual integration into the broader school curriculum.

\subsection{Better legislation and regulation}

According to the National STI Strategy and GoA commitment, the following State budget Funds are to be coordinated by ARTI

- The Fund for National Research and Development Programs

- The Fund for Research Infrastructure

- The Fund for Center of Excellence in research

- The Fund for the transfer of technology and innovation

- The Fund for new researchers

- The Fund for the Brain Gain Program

- The Fund for International Programs (bi-lateral and multilateral (see below)

While it was set up by the National Strategy and Commitment of the GoA to manage these seven different Funds in reality, ARTI is currently only managing the National Programs and the International Programs (two out of seven Funds), whereas the others still remain under the control of the Ministry of Education and Science or the Council of Ministers. Eventually ARTI will control a much larger budget once the remaining five Funds (including the Fund for Infrastructure which is supported by €3.3m from the World Bank) are moved under its purview.

The annual budget for the National Research Programs 2010 was used at $95.26 \%$. Of the money s pent, $44.79 \%$ was allocated to research studies and $55.21 \%$ allocated to equipment related to the projects implemented. The table below shows the sectorial/program allocation of the funding grants awarded by ARTI in 2010 (reported by ARTI in Euros ).

Tab. 2 Funding Grants awarded by ARTI in 2010

\begin{tabular}{|l|l|}
\hline National Programs & Grants awarded by the agency at $\mathbf{1 0 0} \%$ \\
\hline Information systems and Technologies(ICT) & $223,164.00$ \\
\hline Health & $71,640.00$ \\
\hline $\begin{array}{l}\text { Agriculture (veterinary, zoo-technical, Food and } \\
\text { Biotechnology) }\end{array}$ & $313,606.60$ \\
\hline Biodiversity and Environment & $65,021.77$ \\
\hline Water and Energy & $97,133.50$ \\
\hline Materials & $19,956.55$ \\
\hline Social Sciences and Albanology & $113,933.23$ \\
\hline Institute "Albshkenca" & $27,059.55$ \\
\hline Total & $931,515.28$ \\
\hline
\end{tabular}

\section{CONCLUSIONS}

We are all in uncharted territories, and we will have much to learn from the experiments of each other.

The fact that knowledge is, in important ways, a public good and that there are important externalities means that exclusive or excessive reliance on the market may not result in economic efficiency. The challenge is to find the best partnership between private and public sector.

Throughout the world this new perspective is having profound effects on public policy.

The main problems faced from Albanian's National Research and Innovation system are to address as follows:

- Low level of innovation and performance in the national research and innovation system

While we have a good performance in attracting foreign direct investments we lag behind in innovation and technology. This is showed by very low levels of GERD, low technology and innovation level. Albanian firms prefer to purchase technologies rather than developing own technologies. Albania is ranked 78 out of 123 for business sophisticated, 119 for "capacity for innovation comparing with 64 of Croatia and 86 for Macedonia. Albania is ranked even lower for"the quality of scientific research institutions". 
- Lack of statistics on R\&D which will make comparable with other countries. Worse this problem seems to appear regarding private sector

- Universities as research center and public research institutions have a limited cooperation with private sector. Albanian Companies doesn't perform R\&D expensive because of lack of incentive taxes and there is no legislation requiring foreign investors to perform R\&D in Albania.

- Lack of Human Resources Capacities. It remains a weak even with the noted program as "Brain Gain" and "Excellence Fund"

\section{RECOMANDATIONS}

-Research and Technology should receive special attention in national planning in the developing countries.

- one of the major factors for marginal science and technology development in the most developing countries have attempted to formulate and adopt a national policy.

In order, to make a realistic plan, not only a vision, but also scientific leadership and investment in scientific enterprise both by government and private sectors are required.

Short -term financial considerations in investment decisions, that have been observed so far in developing countries, will always be more costly and time consuming.

The institutions for scientific education and research oriented, human resources, well-equipped laboratories, modern libraries constitute the minimum requirements of a scientific infrastructure any developing country must provide for. In order, to establish this infrastructure then the support and funding for universities must be increased .

- The science policy in a developing country should be determined in collaboration with the government, universities and industry.

- Only a industry-universities cooperation can communicate technological advances to potential users.

- Developing countries should focused on engineering Universities.

The first action to undertake by Albanian Government is to keep increasing the percentage of GDP dedicated to Universities and Research Institutions.

\section{REFERENCES}

- Albanian Institute of Statistics

- ERAWATCH Country Reports 2011: Albania

- European Commission (2011) Commission Staff Working Paper, Albania 2011. PROGRESS RAPORT

Grossman, G. and Helpman, E. (1991) Innovation and Growth in the Global Economy, MIT Press, Cambridge, MA.

- Griffiths, R., Redding, S., and Van Reenen, J. (2000) 'Mapping The Two Faces of R\&D: Productivity Growth In A Panel Of OECD Industries', CEPR Discussion Paper No. 2457

- $\quad$ http://data.worldbank.org/indicator/GB.XPD.RSDV.GD.ZS

- $\quad$ http://www.instat.gov.al/

- Joseph Stiglitz. Public Policy for a Knowledge Economy

- Keller, W. (2001b) 'International Technology Diffusion' NBER Working Paper Series, No. 8573. Laszlo Tihanyi and Anthony S. Roath Journal of World Business, 2002, vol. 37, issue 3, pages 188-198

- Mayer, Jörg. (2001) 'Technology Diffusion, Human Capital and Economic Growth in Developing Countries', UNCTAD Discussion Paper\#154, UNCTAD Geneva.

- $\quad$ Miller, S.M., and Upadhyay, M.P. (2000) 'The Effects of Openness, Trade

- $\quad$ Ministry of Finance; Budget Programme 2011

- $\quad$ National Strategy of Science, Tecnology and Innovation 2009-2015

- Orientation, and Human Capital on Total Factor Productivity,' Journal of Development Economics, 63, pp. 399-423.

- Technology transfer and Institutional development in Central and Eastern Europe

- $\quad$ www.gov.minfin.al 


\section{LIST OF ABBREVIATIONS}

AADF

ACES

AIDA

ALL

BERD

BITS

BoA

CR

ERA

EU

FDI

FP

GBAORD

GDP

GERD

HERD

HES

ICT

IMF

INSTAT

IT

NAIS

NSDI

NSSTI

OECD

$R \& D$

RTDI

SME

STI

UNESCO
Albanian-American Development Foundation

Albanian Center of Excellence in Science

Albanian Investment and Development Agency

Albanian Lek

Business Expenditures for Research and Development

Business Innovation and Technology Strategy

Bank of Albania

Country Report

European Research Area

European Union

Foreign Direct Investment

European Framework Programme for Research and Technology

Government Budget Appropriations or Outlays on R\&D

Gross Domestic Product

Gross Domestic Expenditure on R\&D

Higher Education Expenditure on R\&D

Higher Education Sector

Information and Communications Technology

International Monetary Fund

Albanian Institute of Statistics

Information Technology

National Agency for Information Society

National Strategy for Development and Integration

National Strategy of Science, Technology and Innovation

Organization for Economic Cooperation and Development

Research and development

Research Technological Development and Innovation

Small and Medium-Sized Enterprise

Science Technology and Innovation

United Nations Educational, Scientific and Cultural Organization 